\title{
LESIONS OF THE URINARY ORGANS DURING ABDOMINAL AND VAGINAL HYSTERECTOMY
}

\author{
F. LEANZA, G. BIANCA, G. CINQUERRUI, S. CASCHETTO
}

\author{
1ST CLINIC OF OBSTETRICS AND GYNAECOLOGY \\ UNIVERSITY OF CATANIA
}

\begin{abstract}
Key words: ureteral injury, bladder damage, bysterectomy
\end{abstract}
Parole chiave:

SUMMARY: the lesions of the urinary organs of a iatrogenic origin correlated to bysterectomy surgery almost exclusively concern the ureter and the bladder. Lesions of the urinary organs caused during abdominal and vaginal hysterectomy for benign pathology were studied at the 1st Clinic of Obstetrics and Gynaecology of the University of Catania between 1st January 1989 and 31st December 2000. During this period 3,138 hysterectomies were performed, of which 2, 765 (88.11\%) abdominally and 373 (11.89\%) vaginally. Altogether there were 11 (0.35\%) iatrogenic lesions of the urinary excretory organs and these included 5 (0.15\%) ureteral lesions and $6(0.19 \%)$ bladder lesions. There were no lesions of the urethra. In 2, 765 abdominal bysterectomies $4(0.14 \%)$ ureteral lesions and $4(0.14 \%)$ bladder lesions occurred, and in 373 vaginal hysterectomies one (0.27\%) ureteral lesion and 2 (0.54\%) bladder lesions occurred. In all cases, after adequate treatment the urinary organs healed completely. 


\section{INTRODUCTION}

Lesions of the urinary organs caused by abdominal and/or vaginal hysterectomy are always a problem since, despite the progress achieved in surgery, accidents still occur during surgery, and this can lead to iatrogenic damage, although in a more restricted way.

The current data of the literature report that altogether, ureteral damage varies between $0.5-1 \%$ during abdominal hysterectomy and $0.1 \%$ during vaginal hysterectomy(1) and iatrogenic damage to the urinary excretory organs caused by gynaecological surgery is altogether 1-2\%; bladder lesions occur more often than ureteral lesions with a ratio of $5: 1(2)$. The iatrogenic ureteral lesions are caused by gynaecological surgery in $42 \%$ of cases, by general surgery in $25.5 \%$, by vascular surgery in $21.1 \%$ and finally by urological surgery in $10.5 \%$ of cases(3).

E. Lambaudie et al. (2000) report 15 $(0.9 \%)$ bladder lesions and one (0.06\%) ureteral lesion in 1,604 hysterectomies for benign pathology(4). In 3,076 vaginal hysterectomies, P. Methevet et al. (2001) report $1.7 \%$ of lesions of the urinary organs, consisting of 54 bladder lesions and just one ureteral lesion(5). No significative difference is reported between the percentage of abdominal post-hysterectomy (0.40\%) and vaginal post-hysterectomy $(0.47 \%)$ iatrogenic lesions (6).

The conditions that make ureteral damage more likely during hysterectomy are the fixedness of the uterus, endometriosis, anomalies of the course and of the number of ureters, lateralisation of the cervix and pelvic abscess.
The conditions that make bladder lesions more likely are strong adherences from previous pelvic surgery and from the dislocation at the bottom of the trigone in the presence of serious prolapse of the anterior compartment.

The moments of greatest risk of possible ureteral lesions during total hysterectomy, whether abdominal or vaginal, are the ligature of the uterine vessels and cardinal ligaments.

If an adnexectomy is associated with the hysterectomy, the ligature of the infundibulopelvic ligament is an equally risky moment for the ureter, particularly in vaginal hysterectomy, when the ovary is stretched upwards, is adherent and the infundibulopelvic ligament is abnormally short.

The various types of ureteral lesions are as follows: crushing, ligature, section, angle, devascularization, and excision of a tract of the ureter.

Bladder lesions are almost always the consequence of incisions, lacerations or accidental transfixions.

The aim of our study was to evaluate the iatrogenic damage to the urinary organs as a consequence of abdominal and vaginal hysterectomy operations performed at the 1st Clinic of Obstetrics and Gynaecology of the University of Catania between 1st January 1989 and 31st December 2000 and to suggest the most suitable preventative measures.

\section{MATERIALS AND METHODS}

The gynaecological clinical files from between January 1989 to December 2000 were studied. During this period, which covers more than a 
decade, 3,138 hysterectomies were performed of which 2,765 (88.11\%) abdominally and 373 (11.89\%) vaginally. The clinical pathologies and surgical procedures that contributed to cause the iatrogenic lesions were studied. If the ureteral lesion was discovered in time, the surgical manoeuvres responsible for the lesion were studied; if the lesion was discovered late, the pathognomonic symptomatology was studied, as well as the clinical-diagnostic controls that had led to the identification of the lesion. The therapies used to treat the lesions and the short and long-term results were also analysed.

\section{RESULTS}

There were $11(0.35 \%)$ lesions of the urinary excretory organs including ureteral and bladder lesions. There were no lesions of the urethra.

Altogether there were 5 (0.15\%) ureteral lesions, 4 (0.14\%) of which occurred during 2,765 abdominal hysterectomies and $1(0.27 \%)$ during 373 vaginal hysterectomies.

There were $6(0.19 \%)$ bladder lesions, of which $4(0.14 \%)$ occurred during abdominal hysterectomy and 2 (0.54\%) during vaginal hysterectomy (Table I).
All the ureteral lesions were localised in the pelvic segment of the ureter and had occurred near the intersection with the uterine vessels. Two of the 4 ureteral lesions that occurred during hysterectomy were recognised early and 2 late. The first ureteral lesion occurred in a 73-year-old patient during total hysterectomy with bilateral adnexectomy for glandular polypoid hyperplasia of the endometrium and concerned the right ureter. A longitudinal pubo-umbilical laparotomy was performed. The uterus and adnexa were of a regular volume. The right ureter was resected and unintentionally ligatured to the intersection with the uterine artery. The uterus was particularly fixed. Only after removing the pezzo operatorio???, when the peduncles were checked, was it noticed that the ureter, together with the vascular peduncle, had been completely resected. After a cystotomy and the mobilization of the proximal ureteral peduncle, and after applying the ureteral stent, the peduncle was implanted in the bladder again with an anti-reflux technique. After the operation there was no fever, diuresis was regular and recovery satisfactory. After 15 days both the ureteral stent and the transureteral bladder catheter were re-

\section{Table I}

Ureteral lesions

$4(0,14 \%)$

$1(0,27 \%)$
Bladder lesions

$4(0,14 \%)$

$2(0,54 \%)$

Vaginal Hysterectomy (373) 
moved. Micturition started again regularly and no anomalous urine loss was observed. A urography confirmed recovery.

The other iatrogenic lesion of the ureter discovered intra-operatively occurred in a 32-year-old patient, who had already had two caesarean sections, and who underwent a caesarean section at the $40^{\text {th }}$ week of pregnancy. Because of post-partum atony and metrorrhagia, the patient underwent total hysterectomy with left adnexectomy. The operation was particularly investigative and the precise moment when the lesion occurred was not recorded. After the hysterectomy had been performed, during the intra-operative control, a lesione di continuo (continuous lesion???) of the left ureter was noticed, with considerable spreading of urine into the abdomen. After fixing a ureteral stent a ureterocystoneostomy was performed. The post-operative course was regular, the ureteral stent and the catheter were removed after 15 and 18 days respectively, the patient recovered and was discharged. The ultrasound, urographic and clinical controls confirmed recovery.

In two other cases the ureteral lesion occurred during total laparohysterectomy with bilateral adnexectomy for uterine fibromyomas, but it was not recognized intra-operatively. Neither of the operations presented particular difficulties. After a few days, around 10 days for one patient and around 15 days for the other one, the patients complained of a leakage of liquid that appeared to be urine, from the genitals. After placing some gauze in the vagina the topical methylene blue test was performed in the bladder and had a negative outcome, and then the systemic carmine indigo test was carried out with a positive outcome. In order to complete the diagnosis an ultrasound examination of the urinary organs, urography and cystoscopy were performed. The insertion of a double "J" ureteral stent left in place for two months allowed the lesion to heal.

The only case of ureteral lesion during vaginal hysterectomy with bilateral adnexectomy concerned a 78year-old patient with a severe prolapse of the pelvic organs. The diagnosis took place post-operatively. From the day after the operation the patient began to complain of increasing pain in correspondence with the loggia(calix???) of the left kidney. An ultrasound examination of the urinary organs was performed and showed hydronephrosis of the left ureter, confirmed later with an intravenous urography. An attempt was made at inserting a double "J" ureteral stent through cystoscopy, but this manoeuvre was impossible because of the tight stenosis in correspondence with the left ureteral meatus. After 30 days a ureterocystoneostomy was performed with anti-reflux plastic surgery.

Four of the 6 bladder lesions occurred during total abdominal hysterectomy for uterine fibromyomas and 2 during vaginal hysterectomy: 5 lesions were discovered intra-operatively and were repaired appropriately with a double layer of bladder wall sutures and only one lesion was not recognized during the operation.

In the only case that was not discovered intra-operatively, the patient was a 48-year-old, with a total hys- 
terectomy, retro-pubic colposuspension according to Burch, obliteration of the Douglas according to Moskowitz and colpoperineoplasty.

After 5 days the catheter was removed and the patient referred an abundant quantity of urine from the vagina (fondo???). The diagnosis of vesicovaginal fistula was made after a positive methylene blue test in the bladder and after cystoscopic confirmation. A permanent catheter was placed in the bladder. After 10 days the transureteral catheter was removed, but the fistula was still present. The catheter was put back and kept in place for 60 days, then removed, after which the anomalous urine loss disappeared. The clinical, ultrasound, urographic and cystoscopic controls confirmed recovery.

\section{DISCUSSION}

Iatrogenic lesions of the urinary organs are still a problem; in any case the aim is to avoid them and reduce their incidence to within acceptable limits. In our Institute the incidence of ureteral lesions $(0.15 \%)$ and that of bladder lesions (0.19\%) can be compared to the data of the literature, which report a percentage for iatrogenic lesions of the urinary organs during gynaecological surgery varying between $0.1 \%$ to $1 \%(1,2)$.

The problem mainly affects the patient, the surgeon and the post-operative management, through a common commitment that includes the following:

- rational and accurate anatomical knowledge;

- carrying out all the manoeuvres necessary to avoid a lesion;

- recognition of damage in case of a lesion and appropriate repair;

- careful clinical and instrumental evaluation of the patient post-operatively and when she is discharged in order to avoid any asymptomatic ureteral lesions.

Anatomical knowledge includes not only the theoretical study of the various organs, but also practical intra-operative recognition, specially of the ureter which may have an anomalous course and be of an anomalous number.

The measures adopted to avoid ureteral lesions include the following: a good vision of the (campo operatorio)surgical area??? with sufficient illumination and exposure of the tissues, an appropriate traction of the uterus in a contralateral direction particularly during clamping of the uterine vessels and the cardinal ligaments, a correct forcipressure section and clearly identified ligature of the tissues, a good preparation of the ureters avoiding skeletization with consequent devascularization and careful cleaning of the (campo operatorio)surgical area??? in case of bleeding in the areas at risk for ureteral lesions. The preoperative insertion of ureteral stents may be useful when the operations are particularly at risk, as in the case of endometriosis or neoplasias involving the ureter.

As for the preventive measures, for bladder lesions it is advisable to open the parietal peritoneum as high as possible during abdominal hysterectomy, and in the parauterine site during vaginal hysterectomy, to avoid bladder scollamenti per via smussa and diathermocoagulation of abundant tis- 
sue and finally to prefer free ligatures rather than transfixed stitches in case of perivesical bleeding.

After a particularly difficult moment of surgery it is always necessary to revalue the operation performed, after identifying the ureter and the structures that have been sutured. If the ureter has been sectioned, it has to be inserted in the bladder again, possibly with an anti-reflux technique or by fixing the bladder wall to the psoas muscle, and if the lesion has occurred more than $5 \mathrm{~cm}$ from the uterine artery, one has to perform a terminoterminal ureter-ureteral anastomosis. In other cases, if the damage is slight, and there are no lesioni di continuo(continuous lesions???) it may be sufficient to insert a ureteral stent, which can be inserted in cystoscopy or, directly, after making a small longitudinal incision of the bladder vault. Finally, we consider a postoperative control important in order to identify any anomalous loss of urine. In our Institute, for the last few years, apart from the normal gynaecological visit before discharging the patient, an ultrasound examination of the urinary organs has been performed, with an evaluation of the post-micturition residue and control of the normal ureteral perviousness.

In cases of suspected ureteral lesion, the following examinations are useful: systemic dye test (in order to evaluate any ureteral spread), ultrasound examination (to define the presence of ureterohydronephrosis), urography (to identify the site of the lesion) and cystoscopy (to exclude bladder lesions). If the ureteral lesion is discov- ered late, the insertion of an endoureteral stent should always be attempted in order to resolve the damage; this can be performed retrogradely by cystoscopy, or anterogradely under radioscopic control.

As for the bladder lesions, if they are discovered during surgery, repair with a double layer of sutures (the first layer muscle-muscular mucosa-excluded and the second introflexed) using slow absorption materials is sufficient for recovery. If a vesicovaginal fistula occurs, one has to immediately insert a bladder catheter that should be left in place for one or more weeks until the lesion has completely healed; only in exceptional cases does one perform more reparative surgery, which can be carried out either abdominally or vaginally.

\section{CONCLUSIONS}

From our experience it appears that:

- the intra-operative recognition of the ureteral lesion and appropriate repair lead to recovery;

- in so-called "difficult hysterectomies" it is always necessary to evaluate the upper urinary organs after the operation (ultrasound examination and urography where necessary);

- a ureteral lesion discovered postoperatively can heal after inserting a stent;

- it is easier to identify a bladder lesion intra-operatively and repair it;

- permanent bladder catheterisation (up to 60 days) can allow a vesicovaginal fistula to heal. 
Correspondence to:

Prof. Vito Leanza

Via Garibaldi,1

98033 Cesarò (ME)

FAX I Clinica Ost. e Gin. CT

$\mathrm{N}^{\circ} 095-316833$

\section{REFERENCES}

1 - THOMPSON JD:

Te Linde's operative gynecology 8-th edition

Philadelphia, JB Lippincott, 1977;1135-1173.

2 - WALTERS MD, KARRAM MM:

Urogynecology and Reconstructive Pelvic Surgery.

2nd ed. St Luis, 1999:377-386.

3 - GUTIRREZ GARCIA R, ROCA EDREIRA A, MARTIN GARCIA B, HERNANDEZ RODRIGUEZ R, PORTILLO MARTIN JA, GUTIERREZ BANOS JI, CORREAS GOMEZ MA, DEL VALLE SCHAAN JI, VILLANUEVA PENA A, DE DIEGO RODRIGUEZ E:

Iatrogenic ureteral lesions in open surgery: review of 10 years.

Actas Urol Esp 1999 Apr;23(4):323-32.

4 - LAMBAUDIE E, BOUKERROU M, COSSON M, QUERLEU D, CREPIN G:

Hysterectomy for benign lesions: peroperative and early postoperative complications. Ann chir 2000 May;125 (4):340-5.

5 - MATHEVET P, VALENCIA P, COUSIN C, MELLIER G, DARGENT D:

Operative injuries during vaginal hysterectomy.

Eur J Obstet Gynecol Reprod Biol 2001 Jul;97 (1):71-5.

6 - GOODNO JA, POWERS TW, HARRIS VD:

Ureteral injury in gynecologic surgery: A ten-year review in a community hospital.

Am J Obstet Gynecol 1995; 172:1872-22. 